\title{
Isorhythmic Atrioventricular Dissociation
}

National Cancer Institute

\section{Source}

National Cancer Institute. Isorhythmic Atrioventricular Dissociation. NCI Thesaurus. Code C62248.

An electrocardiographic finding of a type of atrioventricular dissociation characterized by the atria ( $P$ waves) and ventricles (QRS complexes) beating at similar rates, although independently. (CDISC) 